"This paper is a preprint of a paper accepted by IET Generation, Transmission \& Distribution and is subject to Institution of Engineering and Technology Copyright. When the final

version is published, the copy of record will be available at the IET Digital Library"

\title{
Forecast Ratio and Security Analysis of Rating Forecasting Methods in an Overhead Line
}

\author{
Igor Albizu $^{1 *}$, Elvira Fernandez ${ }^{2}$, A. Javier Mazon ${ }^{2}$, Rafael Alberdi ${ }^{2}$ \\ Dept. of Electrical Engineering, University of the Basque Country UPV/EHU \\ ${ }^{1}$ Faculty of Engineering Gipuzkoa, Otaola Etorbidea 29, 20600, Eibar, Spain \\ ${ }^{2}$ Faculty of Engineering Bilbao, Alameda Urquijo s/n, 48013, Bilbao, Spain \\ *igor.albizu@ehu.eus
}

\begin{abstract}
The actual line rating in overhead lines varies with weather conditions. When a utility defines a rating value for the operation of the line, it takes into account both the security and the forecast ratio. The defined rating is secure if it is below the actual rating. A good rating forecast ratio is obtained when the defined rating is close to the actual rating. Therefore, the aim of a line rating forecasting method is to define a rating value that is close but below the actual value. This paper shows the rating measurements carried out in a pilot overhead line and analyses the performance of several line rating forecasting methods comparing the defined values with the actual ones.
\end{abstract}

\section{Introduction}

The overhead line rating is dynamic because it depends on the wind speed, the ambient temperature and the solar radiation. The actual rating value is higher when the cooling is higher and vice versa. The overhead line rating forecasting methods have a double requirement: good forecast ratio and security. On the one hand, in terms of the line rating, the forecast ratio of the forecasting method quantifies how close the rating estimate is to the actual value. The forecast ratio is defined as the ratio between the forecasted rating and the actual rating. On the other hand, a method is secure if the forecasted rating is lower or equal to the actual rating. The security is relevant because it affects the people and the infrastructure below the line. The good forecast ratio and the security are related. When the forecast ratio is close to $100 \%$, any error in the forecasting could make the forecast ratio go above this value.

According to CIGRE [1], "the highest local conductor temperature will not exceed the maximum design temperature by more than $20{ }^{\circ} \mathrm{C}$ when the line current equals the line rating. The average temperature of a line section will not exceed the maximum design temperature by more than $10{ }^{\circ} \mathrm{C}$ even under exceptional situations and will provide a confidence level of at least $99 \%$ that the conductor temperature will be less than the design temperature when the line current equals the line rating”. The utilities use conservative rating methods. A static value of the rating is assumed based on low wind speed, high ambient temperature and high solar radiation values [1]. The static line rating is secure but its forecast ratio is low.

As an alternative, dynamic line rating (DLR) systems provide the actual rating in real time [2-6]. Some systems measure weather magnitudes whereas other measure direct magnitudes of the line, such as 
the conductor temperature, tension or sag. These systems get good rating forecast ratios with acceptable security level. However, they only provide information about present conditions of the line. Future line rating forecasts are out of the scope of these systems.

However, system operators require not only present but also future rating values starting from a few hours to some days in advance [7]. Several methods have been proposed for the forecasting of the line rating. Some methods use forecasted weather values [8-16]. The ambient-adjusted line ratings are calculated combining forecasted air temperatures and conservative static wind speed and solar radiation values [1]. Other methods are based on the statistics of the wind diurnal variations [17].

This paper analyses some line rating forecasting methods. The data measured in a pilot line are compared with the forecasted values and forecast ratio and security indicators are obtained. Some preliminary results are presented in [18-20], but this paper extends the rating methods and the analysis of the results.

\section{Overhead line rating forecasting pilot project}

A DLR system [21] has been installed in a distribution line in Spain. The measured magnitudes are the conductor surface temperature and current, the conductor mechanical tension, the wind speed and direction, the solar radiation and the air temperature. Measurements are taken every minute from July 2010 to June 2013. This time span is the same for all the statistics and histograms in the following sections.

Weather prediction is provided by the Spanish State Meteorological Agency (AEMET). The numerical weather prediction (NWP) model is the High Resolution Limited Area Model (HIRLAM). This model provides the air temperature at $2 \mathrm{~m}$, wind speed at $10 \mathrm{~m}$ and solar radiation at ground level. The forecast length is $36 \mathrm{~h}$ with $3 \mathrm{~h}$ of resolution and forecasts are updated every $6 \mathrm{~h}$. The mesh size is $0.05^{\circ}$ (latitude: $5.5 \mathrm{~km}$; longitude: $4 \mathrm{~km}$ ).

\subsection{Diurnal variation}

The diurnal variation of the measured and forecasted air temperature and wind speed values is shown in Figure 1. The diurnal patterns have been obtained including all the values of the time period from July 2010 to June 2013. In the case of the wind speed, the equivalent perpendicular wind speed values have been calculated taking into account the effect of the wind speed angle. The resolution of the measurements is one minute. However, for the variation analysis, the measurements have been grouped in groups of one hour time period. The resolution of the forecasts provided by AEMET is 3 hours. 
The percentiles have been chosen taking into account that high air temperature and low wind speed values are related with low cooling conditions. Hence, the $99^{\text {th }}$ percentile of the air temperature is the limit of the worst $1 \%$ air temperature values, whereas the $1^{\text {st }}$ percentile of the wind speed is the limit of the worst $1 \%$ wind speed values. For this reason, in Figure 1, these percentiles have the same colour.

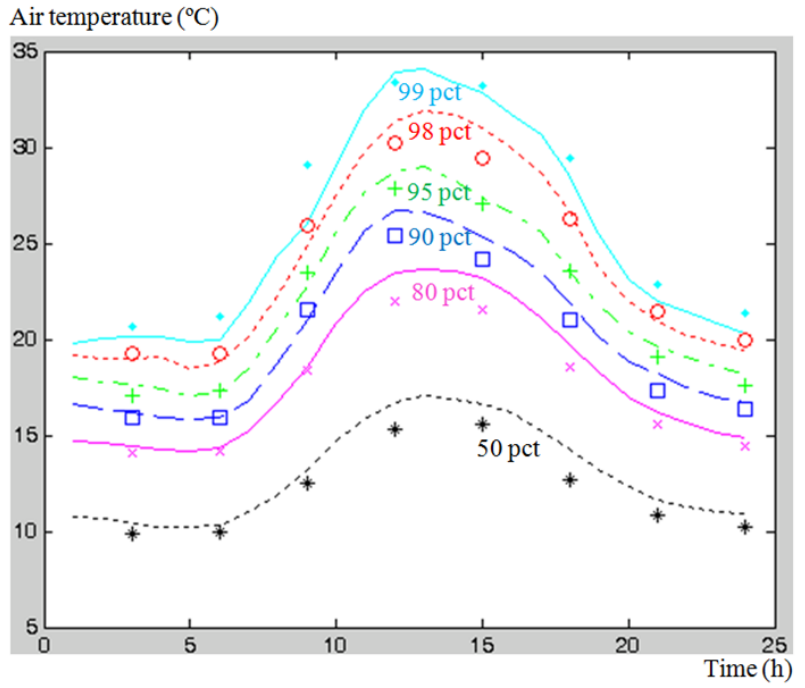

$a$

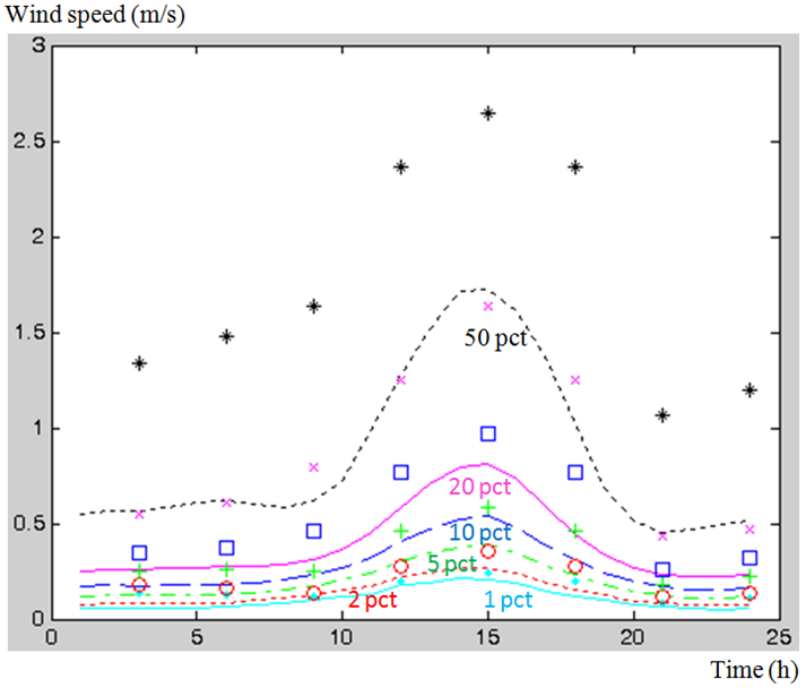

$b$

Fig.1. Diurnal variation of measured (continuous line) and forecasted (dotted line)

a. Air temperature

b. Wind speed

The results show a close agreement between the measured and the forecasted air temperatures. However, the forecasted wind speed values are higher than the measured ones. The results also show lower temperature and wind speed values at night. At night, the cooling is higher because the air temperature is lower, but at the same time, it is lower because of low wind speed values. During the day, the higher air temperature values are compensated with higher wind speed values.

The mean values for the measured air temperature and the wind speed are $12.7{ }^{\circ} \mathrm{C}$ and $1.2 \mathrm{~m} / \mathrm{s}$ respectively. The mean forecasted values for the air temperature and the wind speed are $12.1{ }^{\circ} \mathrm{C}$ and $2 \mathrm{~m} / \mathrm{s}$ respectively.

\subsection{Measured rating}

The maximum allowable conductor temperature is $75^{\circ} \mathrm{C}$. The histogram of the measured ampacity values is shown in Figure 2. The mean ampacity value is $625 \mathrm{~A}$ and the first percentile is $412 \mathrm{~A}$ according to the CIGRE calculation method [22]. The red line shows the value of the static rating. 


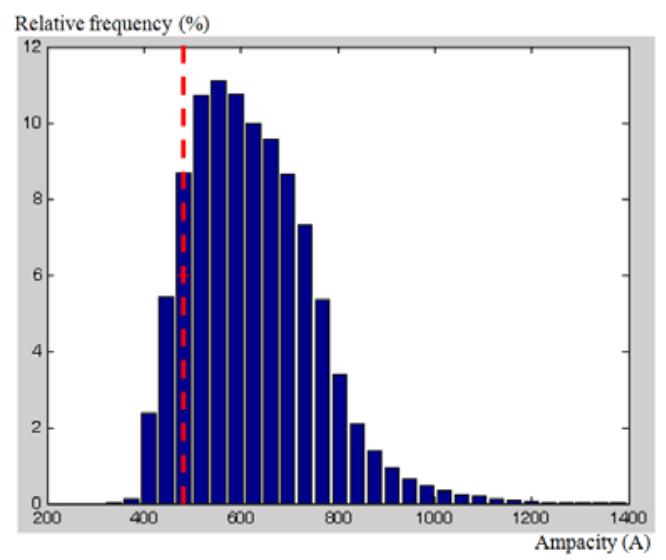

Fig.2. Histogram of the measured ampacity

\section{Analysis of the performance of rating forecasting methods}

The aim of the analysis is to compare some relevant methods to address the importance of quantifying both the forecast ratio and security performance.

With respect to the analysed methods, the widely used static method must be included in the analysis. The forecast ratio and security indicators of the static method are taken as the reference for the evaluation of other methods.

Many methods try to get closer to the actual weather values to improve the forecast ratio. However, they may lose security. The aim of the analysis is to quantify the change in forecast ratio and security of these methods with respect to the static method. Simple forecasting methods have been chosen in order to clearly visualize the effect of the differences between the methods and the static method.

The rating obtained from the weather prediction has also been included in the analysis. As the forecasted wind speed values are higher than the measured ones (Figure 1), unless the weather prediction values are adapted, this method is not suitable for the rating prediction. However, it has been included in the analysis because the results are useful to be aware of the assumed risks when too optimistic predictions are made. The weather forecast based method has also been adapted to improve the security performance of the method. The wind speed has been divided by a constant value. This algorithm is simple, but it is useful to visualize the performance change.

The analysed methods are described firstly. Secondly, the indicators used for the analysis are defined. The results obtained for each method are discussed next.

\subsection{Analysed methods}

3.1.1. Static: The first method considered for the analysis is the static method. A conservative and fixed value of the rating is assumed based on a low cooling assumption. The static method assumes fixed weather values for a large region. The values assumed by the utility in the region of the pilot line are the 
following: solar radiation $\left(1000 \mathrm{~W} / \mathrm{m}^{2}\right)$, wind speed $(0.6 \mathrm{~m} / \mathrm{s})$ and air temperature $\left(26^{\circ} \mathrm{C}\right)$. For these values, the static ampacity is $482 \mathrm{~A}$. A red line in Figure 2 shows the value of the static rating.

3.1.2. Ambient-adjusted: The static method is adapted using the air temperature predictions provided by AEMET. The wind speed and solar radiation are fixed values with the same value as the static method. As the air temperature predictions are variable in time, the rating forecasts are variable too.

3.1.3. Selective ambient-adjusted: The ambient-adjusted method is adapted changing the values of the wind speed according to the method proposed by CIGRE in [1]. For daytime, if the difference between the temperature value of the static rating $\left(26^{\circ} \mathrm{C}\right)$ and the forecasted air temperature is lower than $8^{\circ} \mathrm{C}$, or the forecasted air temperature is higher than the value of the static rating, the assumed effective wind speed is $0.5 \mathrm{~m} / \mathrm{s}$. If it is higher than $8{ }^{\circ} \mathrm{C}$, the assumed wind speed is $0.4 \mathrm{~m} / \mathrm{s}$. For night-time, zero values are assumed for the wind speed and the solar radiation.

3.1.4. Diurnal variation: The static method is adapted changing the wind speed. A diurnal modulation (Figure 3) is applied based on the measured wind speed diurnal variation (Figure 1.b). The mean value of the wind speed is $0.6 \mathrm{~m} / \mathrm{s}$. The air temperature and the solar radiation have fixed values with the same value as the static method.

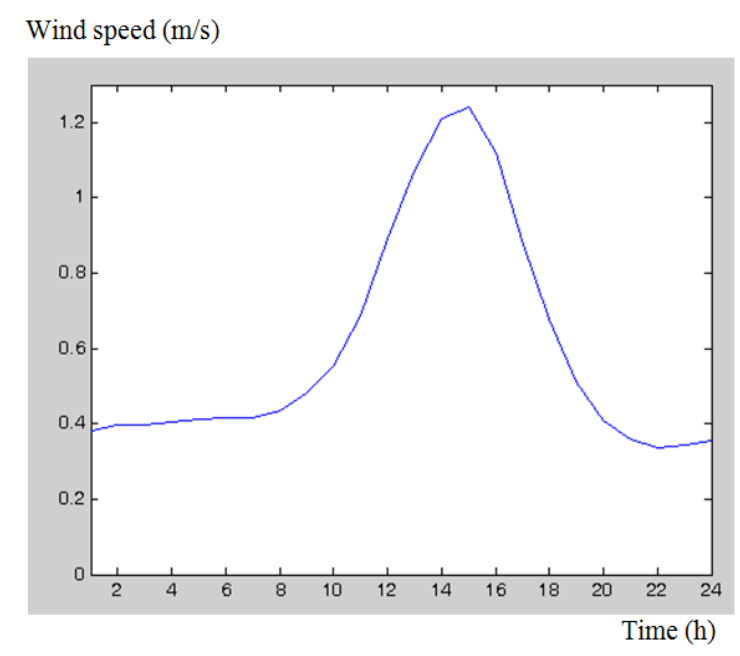

Fig.3. Wind speed diurnal variation

3.1.5. Weather forecast: The ampacity is calculated as a function of the weather forecasts provided by AEMET.

3.1.6. Adapted weather forecast: The weather forecasts provided by AEMET are adapted. The forecasted wind speed is divided by five and the rest of magnitudes are not varied. 


\subsection{Indicators for the analysis}

Forecast ratio and security indicators are obtained for the evaluated rating forecasting methods. The security is a requirement for the utilities whereas a good forecast ratio is desired but it is secondary. One important indicator for the security is the amount of non-secure situations during a period of time. Besides, the relevance of the non-secure situations must be evaluated. The conductor temperature exceedance is calculated assuming the situation where the line loading is equal to the forecasted rating. It must be remarked that it is based in a hypothetical situation and it is not the actual temperature of the line due to the actual loading. The conductor temperature exceedance is a good indicator for the relevance of the overestimated rating.

3.2.1. Security confidence level (\%): This indicator measures the percentage of situations where the forecasted rating is below the measured rating. In other words, it measures the percentage of situations where the forecast ratio is below $100 \%$.

3.2.2. Maximum temperature exceedance $\left({ }^{\circ} \mathrm{C}\right)$ : If the actual loading of the line were equal to the forecasted rating, and with the actual weather conditions, the conductor temperature can be calculated from the thermal balance. The difference between this conductor temperature and the maximum allowable conductor temperature $\left(75^{\circ} \mathrm{C}\right)$ is the temperature exceedance. If the calculated temperature is higher (forecast ratio greater than $100 \%$ ), the difference between both temperatures is the temperature exceedance. The maximum temperature exceedance is the maximum value measured during the monitoring period of the pilot project. It corresponds to an instantaneous value.

3.2.3. Average temperature exceedance $\left({ }^{\circ} \mathrm{C}\right)$ : For the calculation of this indicator, only the situations where the rating is overestimated are taken into account. The temperature exceedance is calculated for all the cases and the average value is obtained.

3.2.4. Temperature increase in the worst $1 \%\left({ }^{\circ} \mathrm{C}\right)$ : This indicator is calculated as the conductor temperature difference between the worst case, corresponding to the maximum temperature exceedance, and the temperature of the $99^{\text {th }}$ percentile. It represents the temperature increase in the worst $1 \%$ cases.

3.2.5. Forecast ratio at $\mathbf{5 0}^{\text {th }}$ (or $\mathbf{2 5}^{\text {th }}$ ) percentile (\%): The forecast ratio is below this value for the $50 \%$ (or $25 \%)$ of the cases.

3.2.6. Average forecast ratio (\%): For the calculation of this indicator, only the situations where the rating is underestimated are taken into account. The forecast ratio is calculated for all the cases and the average value is obtained.

Table 1 shows the indicator values obtained for the analysed rating forecasting methods. 
Table 1 Indicators values for the analysed rating forecasting methods

\begin{tabular}{|c|c|c|c|c|c|c|}
\hline Indicator & Static & $\begin{array}{l}\text { Ambient- } \\
\text { adjusted }\end{array}$ & $\begin{array}{l}\text { Selective } \\
\text { ambient- } \\
\text { adjusted }\end{array}$ & $\begin{array}{c}\text { Diurnal } \\
\text { variation }\end{array}$ & $\begin{array}{l}\text { Weather } \\
\text { forecast }\end{array}$ & $\begin{array}{l}\text { Adapted } \\
\text { weather } \\
\text { forecast }\end{array}$ \\
\hline Security confidence level (\%) & 88 & 67.1 & 89.4 & 91 & 24.6 & 80.2 \\
\hline Maximum temperature exceedance $\left({ }^{\circ} \mathrm{C}\right)$ & 44.4 & 65.7 & 47.6 & 71.8 & 421 & 131.6 \\
\hline Average temperature exceedance $\left({ }^{\circ} \mathrm{C}\right)$ & 12.9 & 20.8 & 13.7 & 16.1 & 58.2 & 23.9 \\
\hline Temperature increase in the worst $1 \%\left({ }^{\circ} \mathrm{C}\right)$ & 21.9 & 14.4 & 20 & 49.2 & 233.8 & 73.3 \\
\hline Forecast ratio at 50th percentile (\%) & 79 & 90.8 & 77.2 & 77.7 & $>100$ & 83.4 \\
\hline Forecast ratio at 25th percentile (\%) & 68.4 & 77.8 & 67.3 & 67.6 & $>100$ & 73.3 \\
\hline Average forecast ratio (\%) & 76.8 & 81.9 & 75.5 & 75.9 & 89.6 & 79.1 \\
\hline
\end{tabular}

\subsection{Static rating}

Figures 4.a shows the cumulative frequency curve of the forecast ratio. The security confidence level is $88 \%$, lower than the $99 \%$ recommended by CIGRE. Fig. 4.b the cumulative frequency curve of the conductor temperature exceedance. The maximum temperature exceedance is $44.4{ }^{\circ} \mathrm{C}$, higher than the CIGRE recommended value $\left(20^{\circ} \mathrm{C}\right)$. The slope of the curves is constant in the central part but it decreases on the edges. The values of the indicators are given in Table 1.

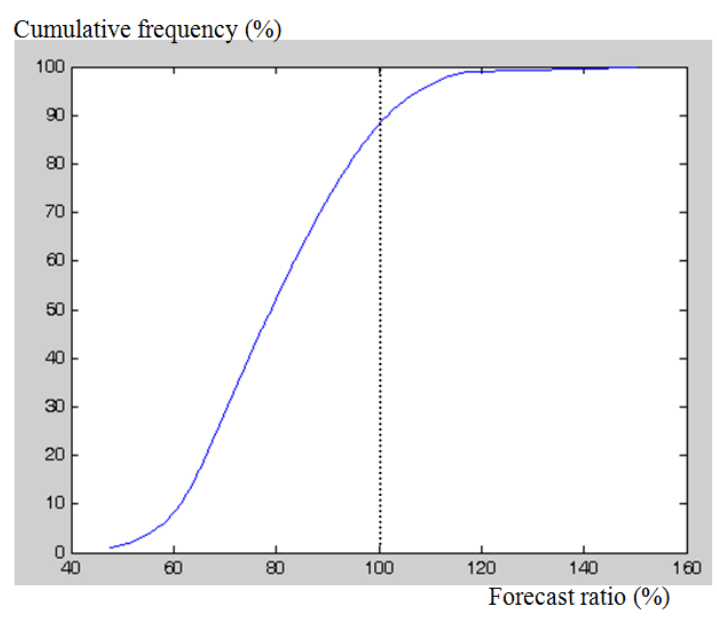

$a$

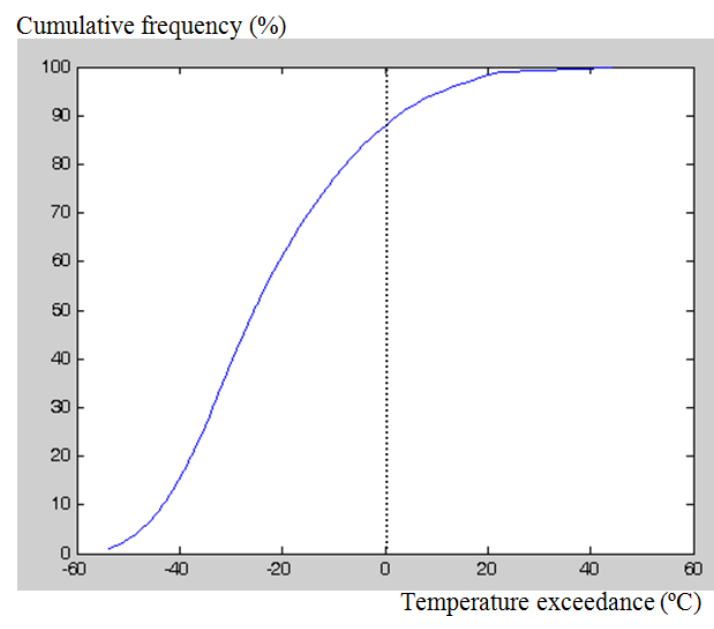

$b$

Fig. 4. Static rating

a. Cumulative frequency of rating forecast ratio (\%)

b. Cumulative frequency of temperature exceedance $\left({ }^{\circ} \mathrm{C}\right)$

One conclusion obtained from the results is that the values the utility use for the static rating are not conservative enough. The local weather values in the pilot line are worse than those considered by the 
utility. This is because the values considered by the utility are the same for a wide region and do not take into account particular weather conditions. If more conservative values are considered (e.g. $0.5 \mathrm{~m} / \mathrm{s}$ instead of $0.6 \mathrm{~m} / \mathrm{s}$ ) the static rating is reduced and as a result the security confidence level is increased and the maximum temperature exceedance is reduced. However, the forecast ratio is reduced too (Table 2).

Table 2 Indicators values for static rating for different wind speed values

\begin{tabular}{lcc}
\hline Indicator & Static & Static \\
& $0.6 \mathrm{~m} / \mathrm{s}$ & $0.5 \mathrm{~m} / \mathrm{s}$ \\
\hline Security confidence level $(\%)$ & 88 & 92.4 \\
Maximum temperature exceedance $\left({ }^{\circ} \mathrm{C}\right)$ & 44.4 & 38 \\
Average temperature exceedance $\left({ }^{\circ} \mathrm{C}\right)$ & 12.9 & 11.4 \\
Temperature increase in the worst $1 \%\left({ }^{\circ} \mathrm{C}\right)$ & 21.9 & 22 \\
Forecast ratio at 50th percentile $(\%)$ & 79 & 75.8 \\
Forecast ratio at 25th percentile $(\%)$ & 68.4 & 65.6 \\
Average forecast ratio $(\%)$ & 76.8 & 74.8 \\
\hline
\end{tabular}

The forecast ratio values are $79 \%$ and $68.4 \%$ for the $50^{\text {th }}$ and $25^{\text {th }}$ percentile. These values are useful in order to assess the benefit of DLR systems or other rating forecasting methods.

Although the rating overestimate period (12\%) is considerably higher than the recommended value ( $1 \%$ ) the conductor temperature exceedance is not so high. The maximum temperature exceedance is 44.4 ${ }^{\circ} \mathrm{C}$. It is higher than the value recommended by CIGRE $\left(20^{\circ} \mathrm{C}\right)$, but the average temperature exceedance is only $12.9^{\circ} \mathrm{C}$. In fact, only a few exceptional situations are responsible for the most dangerous situations. In the worst $1 \%$ of situations (between the 99th and 100th percentiles) the temperature increase is $21.9{ }^{\circ} \mathrm{C}$. This is mainly because of the low wind speed assumption. The range that results in an ampacity overestimate is between $0 \mathrm{~m} / \mathrm{s}$ and $0.6 \mathrm{~m} / \mathrm{s}$. For the air temperature, this range is above $26{ }^{\circ} \mathrm{C}$, and for the solar radiation, it is above $1000 \mathrm{~W} / \mathrm{m}^{2}$. The overestimate range is narrow for the static method.

If the weather values considered for the static rating were changed to be more conservative so that the security confidence level is around $1 \%$, the maximum temperature exceedance would be around $20{ }^{\circ} \mathrm{C}$, which is the recommended value by CIGRE.

The performance of the method has been analysed in order to assess the influence of the diurnal variation of weather conditions. Figure 5 represents the histogram of the $1 \%$ worst cases for the 24 hours of the day. The worst conditions occur during night-time. This is due to low wind speed values as it is shown in Figure 1.b. 


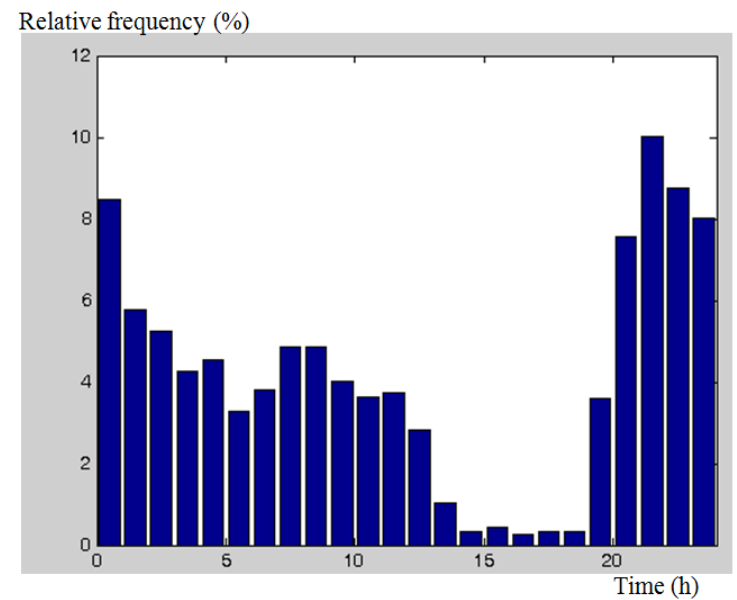

Fig. 5 . Histogram of the 24 hours of the day for $1 \%$ worst cases - Static rating

\subsection{Ambient-adjusted rating}

The static method is adapted using the air temperature predictions provided by AEMET. According to Figure 1a, the forecasted air temperature values are close to the measured ones. Therefore, the air temperature prediction of this method is better than the static method.

However, the results (Table 1) show that the obtained confidence level is lower: $67.1 \%$ for the ambient-adjusted (Fig. 6a) and $88 \%$ for the static. This was expected, because this method is less conservative, with lower air temperature values than the static method, whereas the rest of magnitudes (wind speed and solar radiation) have the same value. The air temperature mean value is $12.7^{\circ} \mathrm{C}$. In other words, the overestimate range for the ambient-adjusted method is wider because the forecasted temperature values are lower. The overestimate range is the range above the forecasted air temperature.

The maximum temperature exceedance is higher than the static value. The reason is the same: the lower air temperature values that result in higher rating values. However, the worst $1 \%$ temperature increase is lower: $14.4{ }^{\circ} \mathrm{C}$ for the ambient-adjusted and $21.9^{\circ} \mathrm{C}$ for the static.

Figure 6c represents the histogram of the $1 \%$ worst cases for the 24 hours of the day. It is similar to the obtained for the static rating. Therefore, the worst conditions are governed by the low wind speed periods as it is shown in Figure 1.b.

The selective ambient-adjusted method is more conservative than the ambient-adjusted because it assumes lower wind speed values. The air temperature values are the same. Therefore, the confidence level is higher (Fig. 6b). In fact, the obtained results are very close to the static rating results and all the indicators have similar values (Table 1). The histogram of the $1 \%$ worst cases shown in Figure $6 \mathrm{~d}$ is also similar but, compared with Figure 5, the first 4 hours of the day do not contribute to the $1 \%$ worst cases. This is because of the zero wind assumed at night-time. 

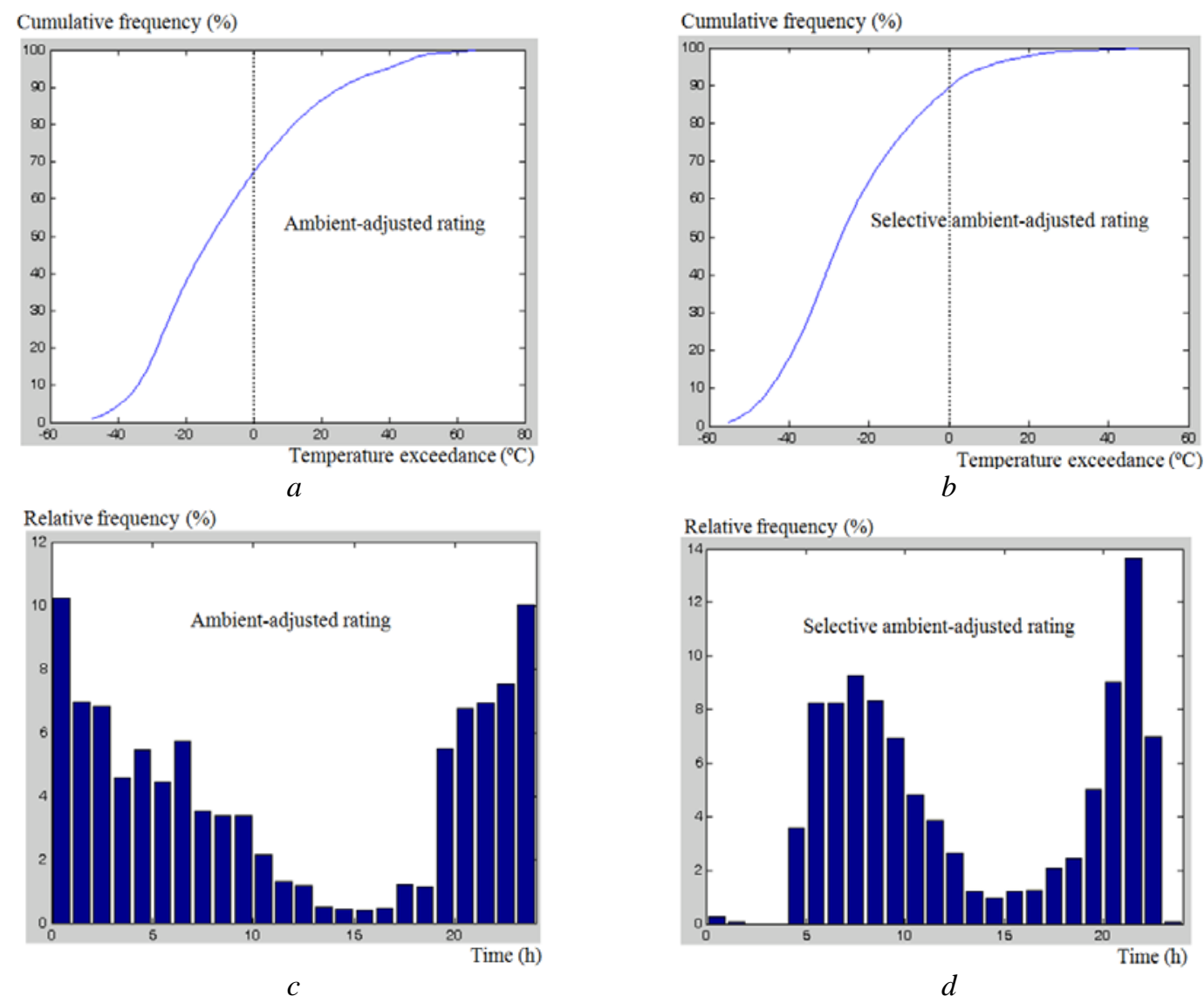

Fig. 6 . Ambient-adjusted rating \& Selective ambient-adjusted rating

a. Cumulative frequency of temperature exceedance $\left({ }^{\circ} \mathrm{C}\right)$ - Ambient-adjusted rating

b. Cumulative frequency of temperature exceedance $\left({ }^{\circ} \mathrm{C}\right)$ - Selective ambient-adjusted rating

c. Histogram of the 24 hours of the day for $1 \%$ worst cases - Ambient-adjusted rating

d. Histogram of the 24 hours of the day for $1 \%$ worst cases - Selective ambient-adjusted rating

\subsection{Diurnal variable rating}

This method is based on the static rating but instead of having a fixed wind speed, the wind speed is modulated according to the measurements diurnal pattern (Fig. 3). The mean value is the same in both cases: $0.6 \mathrm{~m} / \mathrm{s}$. The overestimate region is higher in daytime due to higher wind speed values and lower at night-time due to lower wind speed values.

The security confidence level improves from 88\% to 91 \% (Fig. 7a). However, the maximum temperature exceedance and the temperature increase in the worst $1 \%$ increase their values from $44.4^{\circ} \mathrm{C}$ to $71.8^{\circ} \mathrm{C}$ and from $21.9{ }^{\circ} \mathrm{C}$ to $49.2^{\circ} \mathrm{C}$ respectively. The number of overestimated cases is reduced, which is positive, but the magnitude of the overestimates increase, which is negative. The forecast ratio values are similar in both cases. 
Figure $7 \mathrm{~b}$ shows the histogram of the 24 hours of the day for the $1 \%$ worst cases. It is very different from the previous ones. In this case, the worst overestimates do not occur in night-time but in daytime. This is due to the higher wind speed values assumed during daytime.

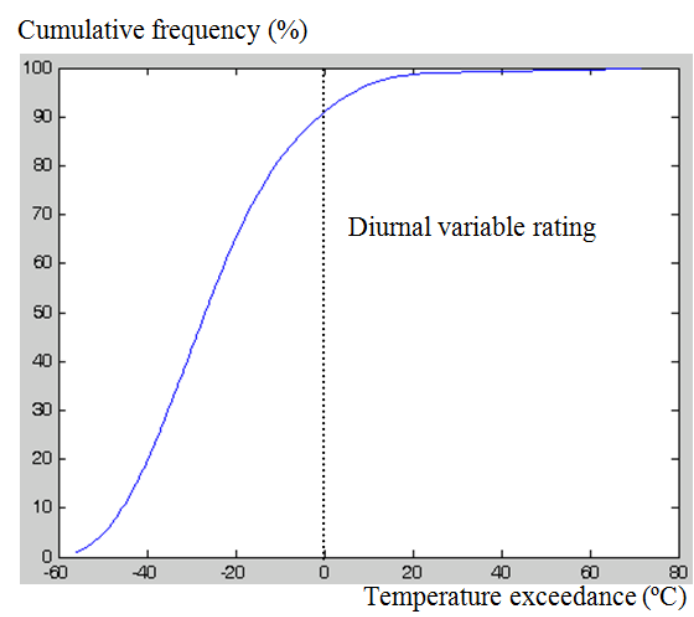

$a$

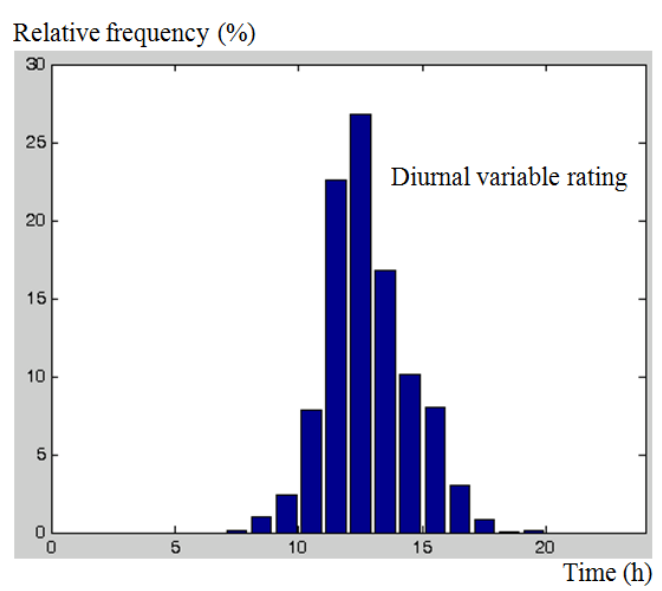

$b$

Fig. 7 . Diurnal variable rating

a. Cumulative frequency of temperature exceedance $\left({ }^{\circ} \mathrm{C}\right)$

b. Histogram of the $1 \%$ worst cases for the 24 hours of the day

\subsection{Weather forecast based rating}

The rating is calculated from the predicted wind speed, air temperature and solar radiation. As it is shown in Figure 1, the forecasted wind speed values are higher than the measured ones. The mean forecasted values for the air temperature and the wind speed are $12.1{ }^{\circ} \mathrm{C}$ and $2 \mathrm{~m} / \mathrm{s}$ respectively. This is reflected in the indicator values. The security confidence level is $24.6 \%$ (Fig. 8a) and the maximum temperature exceedance is $421^{\circ} \mathrm{C}$. The forecasts of AEMET cannot be used directly for rating calculation for the site of the pilot project.

The values given by AEMET have been adapted, dividing the wind speed forecasts by a constant value. The confidence level is increased to 80.2 \% (Fig. 8b) but the maximum temperature exceedance is still high: $131.6^{\circ} \mathrm{C}$. The temperature increase in the worst $1 \%$ is $73.3^{\circ} \mathrm{C}$.

The histogram of the 24 hours of the day for the $1 \%$ worst cases is shown in Figure 8c and 8d. The worst cases occur during the whole day. However, there are fewer cases around 15:00, when the wind values are higher. This is because the thermal balance is more sensitive to errors at low wind speeds. 


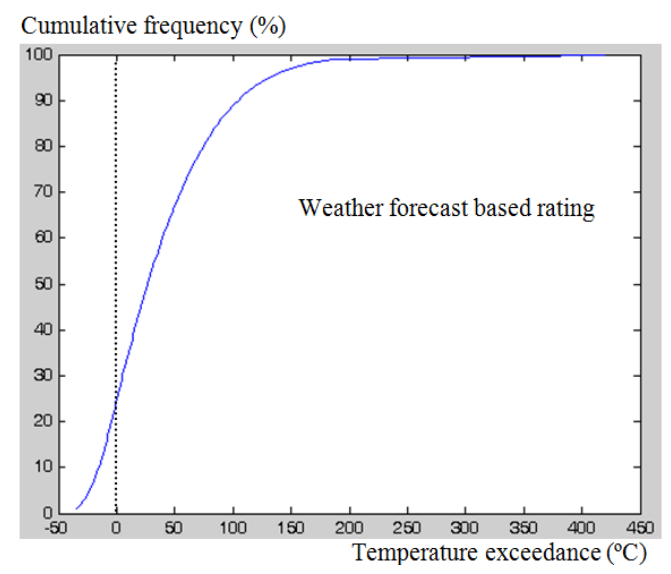

$a$

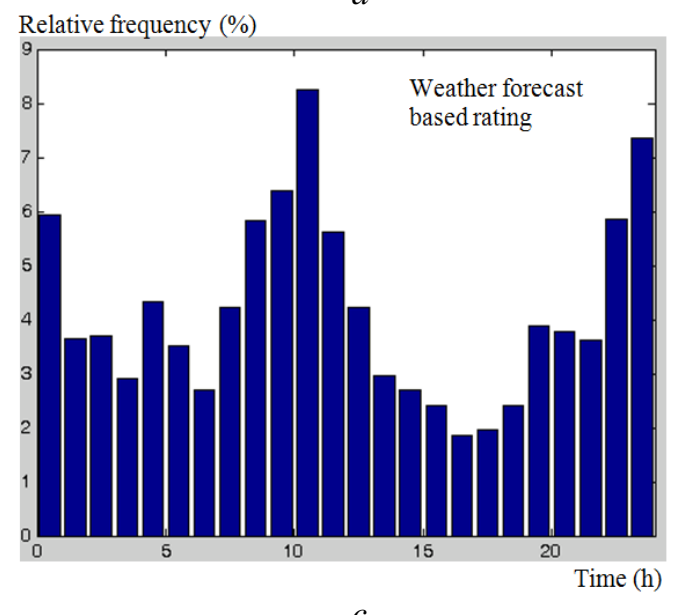

$C$

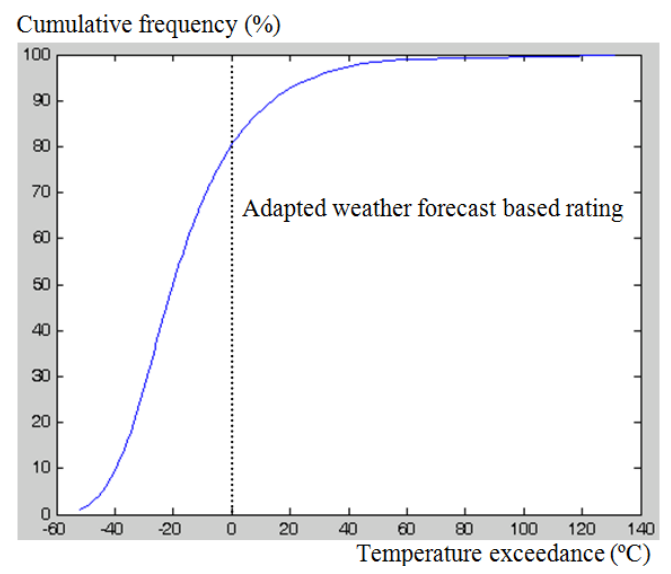

b

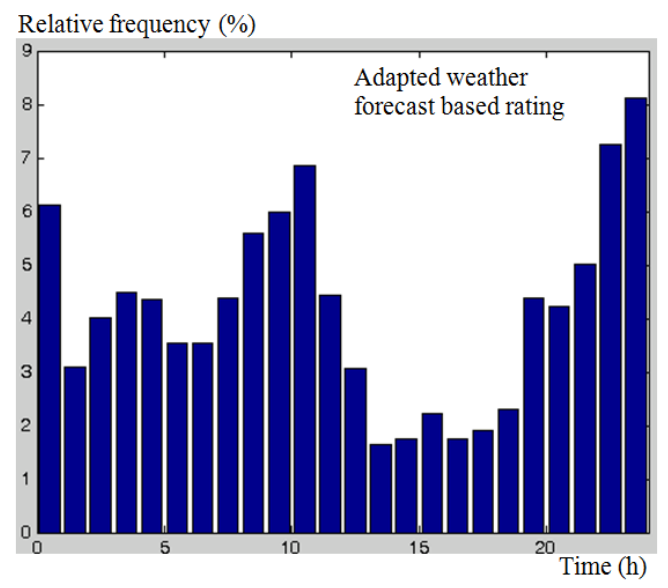

$d$

Fig. 8 . Weather forecast based rating \& Adapted weather forecast based rating

a. Cumulative frequency of temperature exceedance $\left({ }^{\circ} \mathrm{C}\right)$ - Weather forecast based rating

b. Cumulative frequency of temperature exceedance $\left({ }^{\circ} \mathrm{C}\right)$ - Adapted weather forecast based rating

c. Histogram of the 24 hours of the day for $1 \%$ worst cases - Weather forecast based rating

d. Histogram of the 24 hours of the day for $1 \%$ worst cases - Adapted weather forecast based rating

\section{Conclusions}

The line rating obtained from weather measurements in a pilot line has been compared with the rating forecasted by several methods. The obtained results show that monitoring a line provides interesting information of the rating method used by the utility. Firstly, it provides information about the security. The security confidence level and the temperature exceedance values have been obtained for the analysed methods. Secondly, it provides information about the rating forecast ratio of the method. From the obtained forecast ratio values, the utility can decide if the method is useful or they need more advanced methods or even DLR systems.

In order to analyse the results it is important to take into account both the structure of the rating forecasting method and the values assumed by the method. For all the methods, when the assumed values 
are more conservative, the security confidence level is higher and the temperature exceedance is lower but at the expense of lower forecast ratio values.

The results show that an important aspect for a rating method performance is the overestimate range of the method. The overestimate range is related to the difference between the forecasted weather magnitude value and the range of possible values where the rating is overestimated. The static method maintains the weather magnitude values constant in time and close to the overestimate limits: low wind speed and high air temperature and solar radiation. In order to get closer to the actual rating, some methods increase the overestimate range. As a result, they get higher forecast ratio values but when the forecast is not correct the overestimate range is higher and they get higher conductor temperature exceedance values.

For the analysed methods, the static rating and the selective ambient-adjusted rating methods are the most secure. They are characterised by limited overestimate ranges. As a result, the maximum temperature exceedance is low. The rest of methods show higher overestimate ranges and temperature exceedance values. Besides, the benefit obtained in the forecast ratio is not evident.

The defined indicators are general indicators that are calculated considering all the forecasted values but do not take into account the temporal variability. For example, a security confidence level of $91 \%$ means that the $9 \%$ of the cases are overestimated but it does not provide information about the time the cases occur. The variability is represented by the histogram of the 24 hours of the day for the $1 \%$ worst cases. This is an important aspect for the utility in order to adapt the rating forecast performance to the load variations.

\section{Acknowledgments}

This work is financially supported by the Ministerio de Economía y Competitividad, Spain, under the projects DPI2013-44502-R and DPI2016-77215-R (AEI/FEDER, UE). The authors would like to thank Iberdrola utility and the Spanish State Meteorological Agency (AEMET) for the help with the achievement of this project.

\section{References}

[1] CIGRE Brochure 299, Guide for selection of weather parameters for bare overhead conductor ratings, 2006.

[2] CIGRE Brochure 498, Guide for application of direct real-time monitoring systems, 2006.

[3] E. Fernandez, I. Albizu, M.T. Bedialauneta, A.J. Mazon, P.T. Leite, Review of dynamic line rating systems for wind power integration, Renewable \& Sustainable Energy Reviews, Vol. 53, pp. 80-92, 2016.

[4] I. Albizu, E. Fernandez, A.J. Mazon, J. Bengoechea, Influence of the conductor temperature error on the overhead line ampacity monitoring systems, IET Generation, Transmission \& Distribution, Vol. 5, No. 4, pp. 440447, 2011. 
[5] W. Sun, Y. Zhang, C. Wang, P. Song, Flexible load shedding strategy considering real-time dynamic thermal line rating, IET Generation, Transmission \& Distribution, Vol. 7, No. 2, pp. 130-137, 2013.

[6] A. Kubis, C. Rehtanz, Synchrophasor based thermal overhead line monitoring considering line spans and thermal transients, IET Generation, Transmission \& Distribution, Vol. 10, No. 5, pp. 1232-1239, 2016.

[7] S Uski, Estimate method for dynamic line rating potential and economic benefits, Electrical Power and Energy Systems, Vol. 65, pp. 76-82, 2015.

[8] A. Michiorri, H.M. Nguyen, Dynamic Line Rating Forecast, COST WIRE Workshop on « Renewable energy forecasting - state of the art and challenges for the future », 22/10/2014, Paris, France

[9] H.M. Nguyen, J.J. Lambin, F. Vassort et al, Operational experience with Dynamic Line Rating forecast-based solutions to increase usable network transfer capacity, CIGRE Session, Paper C2-103, Paris, 2014.

[10] H.M. Nguyen, J.L. Lilien, P. Schell, Dynamic line rating and ampacity forecasting as the keys to optimise power line assets with the integration of RES. The European project Twenties demonstration inside Central Western Europe, CIRED Conference, Stockholm, 2013.

[11] H.E. Hoekstra, C.P.J. Jansn, J. Hagen et al, "Weather Forecasted Thermal Line Rating Model for the Netherlands, CIGRE Session, Paris, 2012.

[12] T. Ringelband, P. Schäfer, A. Moser, Probabilistic ampacity forecasting for overhead lines using weather forecast ensembles, Electrical Engineering, Vol. 95, No. 2, pp. 99-107, 2013.

[13] A.Michiorri, P.C. Taylor, Forecasting real-time ratings for electricity distribution networks using weather forecast data, CIRED, 2009.

[14] S. Malkin, E. Hsieh, Beyond Real Time: the Computational Challenges of Forecasting Dynamic Line Ratings, FERC Software Tech Conference, June 26, 2013.

[15] A. Michiorri, H.M. Nguyen, S. Alessandrini, J.B. Bremnes, S. Dierer, E Ferrero, B.E. Nygaard, P. Pinson, N. Thomaidis, S. Uski, Forecasting for dynamic line rating, Renewable and Sustainable Energy Reviews, Vol. 52, pp. 1713-1730, 2015.

[16] J.L. Aznarte, N. Siebert, Dynamic Line Rating Using Numerical Weather Predictions and Machine Learning: a Case Study, IEEE Transactions on Power Delivery, 2016.

[17] D. Douglass, Predicting overhead line ratings, IEEE PES OHL/ESMOL Joint Session, Washington DC, 2014.

[18] I. Albizu, E. Fernandez, A.J. Mazon, K.J. Sagastabeitia, M.T. Bedialauneta, J.G. Olazarri, Overhead Line Rating Forecasting for the Integration of Wind Power in Electricity Markets, International Conference on Clean Electrical Power ICCEP, pp. 399-405, Taormina-Italy, 2015.

[19] E. Fernandez, I. Albizu, G. Buigues, V. Valverde, A. Etxegarai, J. G. Olazarri, Dynamic line rating forecasting based on numerical weather prediction, IEEE Powertech, Eindhoven-The Netherlands, 2015.

[20] E. Fernandez, I. Albizu, A. J. Mazon, A. Etxegarai, G. Buigues, R. Alberdi, Power Line Monitoring for the Analysis of Overhead Line Rating Forecasting Methods, IEEE PES PowerAfrica 2016, Livingstone-Zambia, 2016. 
[21] I. Albizu, E. Fernandez, P. Eguia, E. Torres, A.J. Mazon, Tension and Ampacity Monitoring System for Overhead Lines, IEEE Transactions on Power Delivery, Vol. 28, No. 1, pp. 3-10, 2013.

[22] CIGRE Brochure 601, Guide for thermal rating calculations of overhead lines, 2014. 